\title{
Outcomes of contemporary mechanical circulatory support device configurations in patients with severe biventricular failure
}

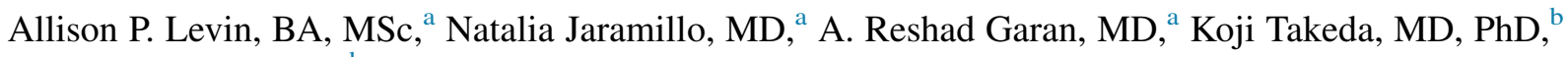 \\ Hiroo Takayama, MD, ${ }^{b}$ Melana Yuzefpolskaya, MD, ${ }^{\text {a }}$ Donna M. Mancini, MD, ${ }^{a}$ \\ Yoshifumi Naka, MD, PhD, ${ }^{b}$ Paolo C. Colombo, MD, ${ }^{a}$ and Veli K. Topkara, MD, MSc ${ }^{a}$
}

\begin{abstract}
Objectives: Severe right ventricular failure often is considered a contraindication for left ventricular assist device (LVAD) therapy and necessitates use of biventricular assist devices (BiVADs). Available options for BiVADs are limited, and comparative outcomes are largely unknown.

Methods: Heart transplant candidates who were registered on the United Network for Organ Sharing waitlist and underwent long-term contemporary LVAD $(\mathrm{n}=3195)$ or BiVAD $(\mathrm{n}=408)$ implantation, from January 2010 through June 2014, were retrospectively analyzed. We evaluated clinical characteristics and outcomes of patients requiring a BiVAD, as well as regional differences in utilization of this technology.
\end{abstract}

Results: Patients requiring a BiVAD were younger (48.9 vs 53.3 years), had a higher proportion of nonischemic disease $(69.1 \%$ vs $58.2 \%)$, a higher bilirubin level $(0.9$ vs $0.7 \mathrm{mg} / \mathrm{dL})$, and a lower 6-month survival rate $(68.1 \%$ vs $92.7 \%)$ after device implantation (all $P<.05$ ). Postimplantation and posttransplantation survival was comparable for commonly used BiVAD configurations, including total artificial heart, continuous flow BiVAD, a continuous-flow LVAD coupled with a right-sided device, and pulsatile flow. Significant variation was found in regional utilization of these devices, regardless of differences in transplantation waitlist times. A large body surface area was an independent predictor of mortality on a BiVAD (hazard ratio $=2.12, P=.017$ ).

Conclusions: Outcomes of patients requiring a BiVAD remain poor in the contemporary device era, regardless of the configuration used. Among other clinical factors, body surface area should be incorporated into decision making for device selection in these patients. (J Thorac Cardiovasc Surg 2016;151:530-5)

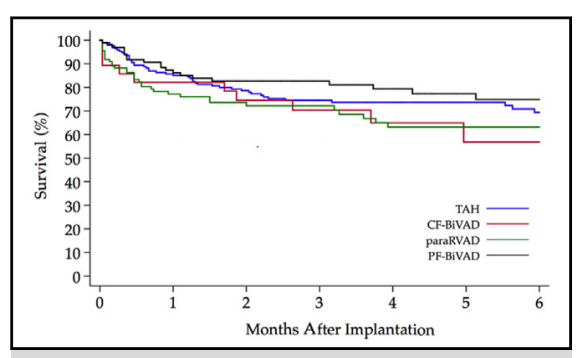

Postimplantation survival on BiVADS

\section{Central Message}

Outcomes of patients who undergo device implantation for biventricular support remain poor, regardless of the device type.

\section{Perspective}

Utilization of biventricular support devices differs significantly by geographic region, independent of transplantation waitlist times. Large body size is an important risk factor for mortality on biventricular device support, and therefore should be incorporated into selection decisions regarding the appropriate device type for each candidate. Outcomes of patients who undergo device implantation for biventricular support remain poor, regardless of the device type.

See Editorial Commentary page 536.
丹 Supplemental material is available online.

Continuous-flow left ventricular assist device (CF-LVAD) technology has led to substantial improvements in

From the ${ }^{\mathrm{a}}$ Division of Cardiology, Department of Medicine, and ${ }^{\mathrm{b}}$ Division of Cardiothoracic Surgery, Department of Surgery, New York-Presbyterian/ Columbia University Medical Center, New York, NY.

Received for publication May 21, 2015; revisions received Sept 17, 2015; accepted for publication Oct 8, 2015; available ahead of print Dec 2, 2015.

Address for reprints: Veli K. Topkara, MD, MSc, Center for Advanced Cardiac Care, New York-Presbyterian/Columbia University Medical Center, 622 W 168th St, PH9-977, New York, NY 10032 (E-mail: vt2113@cumc.columbia.edu). $0022-5223 / \$ 36.00$

Copyright (c) 2016 by The American Association for Thoracic Surgery http://dx.doi.org/10.1016/j.jtcvs.2015.10.019 outcomes of patients with end-stage heart failure, for bridge-to-transplantation as well as destination therapy indications. $^{1,2}$ Despite the rapidly increasing CF-LVAD implant numbers and physician experience nationwide, management of right ventricular (RV) failure before and after device insertion continues to be a major challenge in this patient population. ${ }^{3}$ Although direct unloading of the left ventricle leads to a reduction in left-sided filling pressures, and hence RV afterload, RV function may commonly deteriorate after CF-LVAD implantation, owing to increased RV preload, changes in the septal position, and RV geometry, as well as perioperative inflammatory response. Several preoperative risk assessment tools have been developed to determine the risk of $\mathrm{RV}$ failure in patients after they undergo LVAD implantation. ${ }^{4-8}$ 


$$
\begin{aligned}
& \text { Abbreviations and Acronyms } \\
& \begin{aligned}
\text { BiVAD } & =\text { biventricular assist device } \\
\text { BSA } & =\text { body surface area } \\
\text { CF } & =\text { continuous-flow } \\
\text { LVAD } & =\text { left ventricular assist device } \\
\text { PF } & =\text { pulsatile-flow } \\
\text { RV } & =\text { right ventricular } \\
\text { RVAD } & =\text { right ventricular assist device } \\
\text { TAH } & =\text { total artificial heart }
\end{aligned}
\end{aligned}
$$

Abnormal laboratory parameters (elevated bilirubin, blood urea nitrogen, aspartate aminotransferase, creatinine), echocardiographic indices (presence of RV systolic dysfunction, severe tricuspid regurgitation), and hemodynamic findings (higher central venous pressure, lower pulmonary artery pressures, higher central venous pressure/wedge ratio) have been identified as potential predictors of post-LVAD RV failure. $^{4-8}$ Moreover, intraoperative or early postoperative events, such as bleeding and/or sepsis-related vasodilatory conditions, which are not always predictable at the preoperative stage, might contribute to the development of RV failure as well. Given the poor outcomes associated with RV failure, patients who are deemed to be at high risk for this complication may not be offered CF-LVAD implantation without concomitant insertion of right-sided support devices.

Contemporary mechanical circulatory support options for patients with severe biventricular failure include total artificial hearts (TAH), CF-LVADs coupled with a contemporary paracorporeal-RVAD, fully implantable CFbiventricular assist devices (CF-BiVADs), and paracorporeal pulsatile-flow BiVADs (PF-BiVADs). ${ }^{9-12}$ Given the limited number of these patients at any given center, and clustering due to center- or surgeon-specific device preferences, the comparative effectiveness of these device configurations remains largely unknown. ${ }^{13}$ The United Network for Organ Sharing database recently implemented a mechanical circulatory support dataset that provides detailed information regarding device implantation/explantation dates and configurations. Using this dataset, we sought to comparatively analyze outcomes of various BiVAD configurations in patients listed for heart transplantation in the database.

\section{METHODS}

\section{Data Source and Study Population}

The United Network for Organ Sharing provided deidentified patient-level data from the waitlist, for the mechanical circulatory support and transplantation registries. These data included all heart transplant candidates who were registered on the waitlist between 1985 and 2014 . We included adult candidates (aged $\geq 18$ years) who were registered for single-organ, primary heart transplantation, and received a contemporary CF-LVAD or BiVAD (including TAH) as a bridge to transplantation, between January 2010 and June 2014 (Figure E1).
Patients who required temporary left-sided support, noncontemporary durable LVAD and/or RVAD combination, or RVAD insertion after LVAD, were excluded from the analysis. Candidate characteristics present at the time of waitlist registration were collected and comparatively analyzed. For geographic comparisons, The United Network for Organ Sharing Regions are numbered 1 through 11. For the purpose of this analysis, we categorized regions as follows: East (regions 1, 2, and 9); Midwest (regions 7, 8, and 10); South (regions 3, 4, and 11); and West (regions 5 and 6). Use of these data is consistent with the regulation of the Columbia University Institutional Review Board.

\section{Statistical Analysis}

Continuous variables were summarized as mean $\pm \mathrm{SD}$, or median with interquartile range, and were compared using an independent $t$ test and analysis of variance. The $P$ values for pairwise comparisons were adjusted using the Bonferroni correction. Categorical variables were summarized as frequencies and percentages, and were compared using the Pearson $\chi^{2}$ test. Cumulative survival rates of ventricular assist devices were estimated using Kaplan-Meier survival analysis, and compared using the log-rank test. Patients were censored from the analysis at any of the following points: explantation of biventricular support; heart transplantation; and waitlist removal for other reasons. Univariable Cox proportional regression was performed to determine the association of patient characteristics with survival on biventricular support.

The models examined the effect of the following candidate characteristics present at registration on the heart transplantation waitlist: age, gender, body surface area (BSA), race, ABO blood type, heart failure etiology, history of diabetes mellitus, tobacco use, creatinine level, cardiac index, cardiac output, and geographic region. To determine the independent effect of multiple risk factors on waitlist mortality, a multivariable Cox proportional hazard model was utilized. Variables at the $P<.10$ level in unadjusted analyses were considered for inclusion; only variables at the $P<.05$ level, based on the likelihood ratio test, were retained in the final model. Hazard ratios, $95 \%$ confidence intervals, and $P$ values were generated for both univariable and multivariable analyses as measures of strength of association and precision. All analyses were performed with STATA software, version 13 (Stata Corporation, College Station, Tex).

\section{RESULTS}

\section{Characteristics of Patients}

A total of 3195 contemporary CF-LVAD patients, and 408 BiVAD bridge-to-transplantation patients (including TAH) were identified in the United Network for Organ Sharing registry. The BiVAD configurations included the following: TAH in 172 patients; CF-BiVAD in 28 patients; paracorporeal-RVAD in 110 patients; and PF-BiVAD in 98 patients (Figure E1). Patients who required biventricular support had the following characteristics, compared with those who required left ventricular support only: They were significantly younger $(48.9 \pm 13.5$ vs $53.3 \pm 12.0$ years, $P<.001)$; they were more likely to be women $(26 \%$ vs $22 \%, P=.048)$ and to have nonischemic etiology of heart failure $(69 \%$ vs $58 \%, P<.001)$; they had a lower incidence of diabetes $(26 \%$ vs $33 \%$, $P=.003)$ and tobacco use ( $39 \%$ vs $54 \%, P<.001)$, and a lower average body mass index $(26.8 \pm 5.0$ vs $\left.28.1 \pm 4.9 \mathrm{~kg} / \mathrm{m}^{2}, P<.001\right)$ and cardiac index $(2.1 \pm 0.8$ vs $2.2 \pm 0.6 \mathrm{~L} /$ minute $\left./ \mathrm{m}^{2}, P=.009\right)$. They had lower albumin levels ( $3.4 \pm 0.8$ vs $3.6 \pm 0.7 \mathrm{~g} / \mathrm{dL}, P<.001)$, as well as 
TABLE 1. Baseline characteristics of patients with CF-LVAD versus BiVAD implantation

\begin{tabular}{lccr}
\hline \multicolumn{1}{c}{ Variable } & $\begin{array}{c}\text { CF-LVAD } \\
(\mathbf{n}=\mathbf{3 1 9 5})\end{array}$ & $\begin{array}{c}\text { BiVAD } \\
(\mathbf{n}=\mathbf{4 0 8})\end{array}$ & $\boldsymbol{P}$ value \\
\hline Age $(\mathrm{y})$ & $53.32 \pm 11.99$ & $48.85 \pm 13.51$ & $<.001$ \\
Gender, male & $2488(77.9)$ & $300(73.5)$ & .048 \\
BMI $\left(\mathrm{kg} / \mathrm{m}^{2}\right)$ & $28.07 \pm 4.90$ & $26.82 \pm 5.00$ & $<.001$ \\
BSA $\left(\mathrm{m}^{2}\right)$ & $2.07 \pm 0.26$ & $2.05 \pm 0.15$ & .340 \\
Race & & & .823 \\
$\quad$ White & $2116(66.2)$ & $275(67.4)$ & \\
$\quad$ Black & $757(23.7)$ & $91(22.3)$ & \\
$\quad$ Other & $322(10.1)$ & $42(10.3)$ & \\
Ischemic etiology & $1335(41.8)$ & $126(30.9)$ & $<.001$ \\
Diabetes & $1062(33.2)$ & $106(26.0)$ & .003 \\
Blood type O & $1476(46.2)$ & $196(48.0)$ & .610 \\
History of smoking & $1715(53.7)$ & $159(39.0)$ & $<.001$ \\
IABP at listing & $136(4.3)$ & $26(6.4)$ & .052 \\
Cardiac output $(\mathrm{L} / \mathrm{min})$ & $4.82 \pm 1.52$ & $4.34 \pm 1.58$ & $<.001$ \\
Cardiac index $\left(\mathrm{L} / \mathrm{min} / \mathrm{m}^{2}\right)$ & $2.16 \pm 0.64$ & $2.06 \pm 0.78$ & .009 \\
Total bilirubin $(\mathrm{mg} / \mathrm{dL})$, & $0.7(0.5,1.1)$ & $0.9(0.6,1.4)$ & $<.001$ \\
$\quad$ & & & \\
median $(\mathrm{IQR})$ & $3.6 \pm 0.65$ & $3.38 \pm 0.75$ & $<.001$ \\
Albumin $(\mathrm{g} / \mathrm{dL})$ & $1.2(0.92,1.48)$ & $1.2(0.9,1.58)$ & .556 \\
Creatinine $(\mathrm{mg} / \mathrm{dL})$, & & & \\
$\quad$ median $(\mathrm{IQR})$ & & & \\
\hline
\end{tabular}

Values are $\mathrm{n}(\%)$, or mean $\pm \mathrm{SD}$, unless otherwise indicated. $C F-L V A D$, Continuousflow left ventricular assist device; $B i V A D$, biventricular assist device; $B M I$, body mass index; $B S A$, body surface area; $I A B P$, intra-aortic balloon pump; $I Q R$, interquartile range.

higher levels of bilirubin $(0.9$ vs $0.7 \mathrm{mg} / \mathrm{dL}, P<.001)$, compared with those who required left ventricular support only (Table 1). Postimplantation survival was significantly lower in the BiVAD patients, compared with the CFLVAD patients at 1 month ( $83 \%$ vs $98 \%$ ), and at 6 months (68\% vs $93 \%$ ), with a log-rank $P<.001$ (Figure 1 ).

\section{Comparison of Biventricular Support Devices}

For patients undergoing various BiVAD configurations, post hoc analysis of baseline characteristics demonstrated

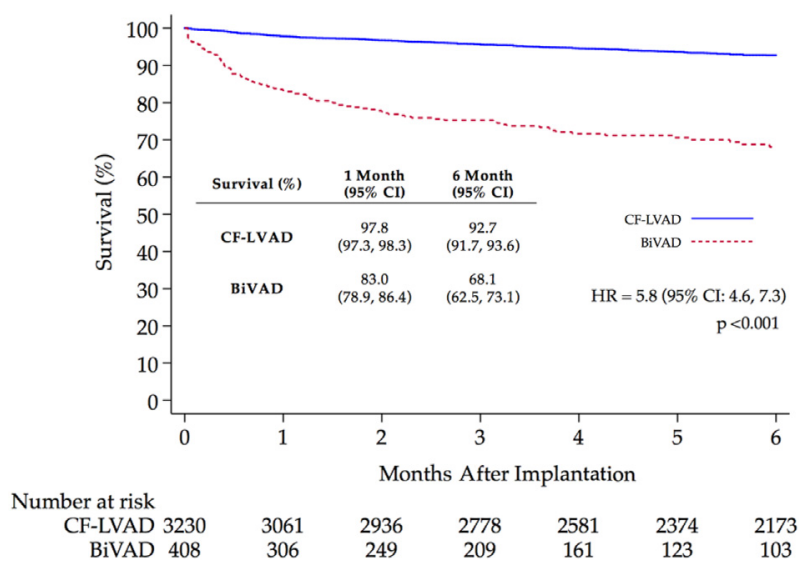

FIGURE 1. Postimplantation survival in patients requiring CF-LVAD versus BiVAD support. $C I$, Confidence interval; $C F-L V A D$, continuousflow left ventricular assist device; $B i V A D$, biventricular assist device; $H R$, hazard ratio. a significantly lower BSA in patients requiring PFBiVAD, compared with those requiring TAH (Table 2). Nonischemic etiology of heart failure was more common in patients who had TAH and CF-BiVAD, compared with the paracorporeal-RVAD and PF-BiVAD groups. Significant regional variation was found in utilization of BiVADS (Figure 2). Preferred BiVAD choices were as follows: TAH and paracorporeal-RVAD in the Midwest and South regions; TAH and PF-BiVAD in the West region; and paracorporeal-RVAD and TAH in the East region $(P<.001)$.

Regional waitlist time did not have an impact on BiVAD preferences, as the registry regions with comparable waitlist times had substantially different device preferences (Table E1). For example, device choices in regions with the longest waitlist times (region 1 vs region 9) and shortest waitlist times (region 5 vs region 8) were significantly different $(P<.001$ in both comparisons). National and regional trends in utilization of BiVAD configurations have demonstrated an increase in use of TAH, paracorporealRVAD, and CF-LVAD, along with a decrease in use of PF-BiVAD, from 2010 to 2013 (Figure E2). Survival on device support was not statistically different among the TAH, CF-BiVAD, paracorporeal-RVAD, and PF-BiVAD groups (Figure 3). Bridge-to-transplantation rates, as well as posttransplantation survival, were comparable among the 4 groups as well (Figure E3).

\section{Predictors of Patient Mortality on Biventricular Support}

Multivariable analysis identified BSA as an independent predictor of mortality in patients who require biventricular support (Table 3). Postimplantation survival at 6 months was $74.2 \%, 75.1 \%, 67.0 \%$, and $57.2 \%$, for patients who are in the BSA quartiles 1 to 4 , respectively, with a logrank $P$ value of .045 (Figure 4). Analysis of device type and BSA group as an interaction term in the regression model showed that patients in the highest BSA quartile on PF-BiVAD support had higher mortality, compared with patients with the lowest BSA on TAH support (Table E2).

\section{DISCUSSION}

This study evaluated clinical risk factors associated with use of BiVADS, as bridge-to-transplantation and outcomes, in an era in which application of this technology is increasing nationally. Our principal findings are as follows. First, patients requiring biventricular support represent a sicker cohort, who are younger, and have nonischemic etiology of heart failure, and have worse outcomes, compared with those requiring LV support only. Second, a significant regional preference was found in use of BiVAD configurations. Third, survival on device support was similar for various BiVAD options. Finally, BSA is a predictor of survival on BiVADs. Taken together, these findings 
TABLE 2. Baseline characteristics of patients undergoing various BiVAD configurations

\begin{tabular}{|c|c|c|c|c|c|}
\hline Variable & TAH $(\mathbf{n}=172)$ & CF-BiVAD $(n=28)$ & Paracorporeal-RVAD $(n=110)$ & PF-BiVAD $(\mathbf{n}=\mathbf{9 8})$ & $P$ value \\
\hline Age (y) & $49.54 \pm 12.96$ & $45.54 \pm 16.51$ & $48.58 \pm 13.56$ & $48.90 \pm 13.55$ & .540 \\
\hline Gender, male & $136(79.1)$ & $21(75.0)$ & $77(70.0)$ & $66(67.4)$ & .150 \\
\hline $\operatorname{BSA}\left(\mathrm{m}^{2}\right)$ & $2.09 \pm 0.26$ & $2.07 \pm 0.29$ & $2.05 \pm 0.32$ & $1.98 \pm 0.32$ & $.046 *$ \\
\hline Ischemic etiology & $44(25.6)$ & $5(17.9)$ & $43(39.1)$ & $34(34.7)$ & .035 \\
\hline Race & & & & & .042 \\
\hline White & $120(69.8)$ & $22(78.6)$ & $69(62.7)$ & $64(65.3)$ & \\
\hline Black & $32(18.6)$ & $5(17.9)$ & $35(31.8)$ & $19(19.4)$ & \\
\hline Other & $20(11.6)$ & $1(3.6)$ & $6(5.5)$ & $15(15.3)$ & \\
\hline Region & & & & & $<.001$ \\
\hline East & $32(18.6)$ & $11(39.3)$ & $38(34.6)$ & $22(22.5)$ & \\
\hline West & $29(16.9)$ & $2(7.1)$ & $17(15.5)$ & $32(32.7)$ & \\
\hline Midwest & $47(27.3)$ & $10(35.7)$ & $20(18.2)$ & $16(16.3)$ & \\
\hline South & $64(37.2)$ & $5(17.9)$ & $35(31.8)$ & $28(28.6)$ & \\
\hline Diabetes & $42(24.4)$ & $5(17.9)$ & $33(30.0)$ & $26(26.5)$ & .391 \\
\hline Blood type $\mathrm{O}$ & $86(50.0)$ & $15(53.6)$ & 49 (44.6) & $46(46.9)$ & .842 \\
\hline History of smoking & $62(36.1)$ & $9(32.1)$ & $48(43.6)$ & $40(40.8)$ & .343 \\
\hline Total bilirubin (mg/dL), median (IQR) & $0.9(0.7,1.4)$ & $0.65(0.4,1.0)$ & $0.9(0.6,1.3)$ & $1(0.7,1.5)$ & .527 \\
\hline IABP & $6(3.5)$ & $2(7.1)$ & $7(6.4)$ & $11(11.2)$ & .098 \\
\hline Cardiac output (L/min) & $4.3 \pm 1.55$ & $4.06 \pm 1.63$ & $3.97 \pm 1.46$ & $4.36 \pm 1.71$ & .349 \\
\hline Cardiac index $\left(\mathrm{L} / \mathrm{min} / \mathrm{m}^{2}\right)$ & $2.04 \pm 0.81$ & $2.01 \pm 0.85$ & $1.94 \pm 0.67$ & $2.23 \pm 0.83$ & .128 \\
\hline Time on BiVAD support (d) & $101.5(39.5,197.0)$ & $97.5(52.5,151.0)$ & $51.5(16.0,151.0)$ & $105.0(38.0,191.0)$ & .073 \\
\hline
\end{tabular}

Values are $\mathrm{n}(\%)$, or mean $\pm \mathrm{SD}$, unless otherwise indicated. East $=$ regions 1, 2, and 9; Midwest $=$ regions 7, 8, and 10; South $=$ regions 3, 4, and 11 ; and West $=$ regions 5 and 6 . $T A H$, Total artificial heart; BiVAD, biventricular assist device; $C F-B i V A D$, continuous-flow BiVAD; $R V A D$, right ventricular assist device; $P F-B i V A D$, pulsatile-flow BiVAD; $B S A$, body surface area; $I Q R$, interquartile range; $I A B P$, intra-aortic balloon pump. ${ }^{*} P<.05$ for pairwise comparison of TAH versus PF-BiVAD.

highlight the need for improvement in treatment strategies and outcomes for patients who have severe biventricular failure necessitating mechanical assistance.

The group of patients who required biventricular support had a higher proportion of nonischemic etiology of heart failure in this analysis. Previous studies have

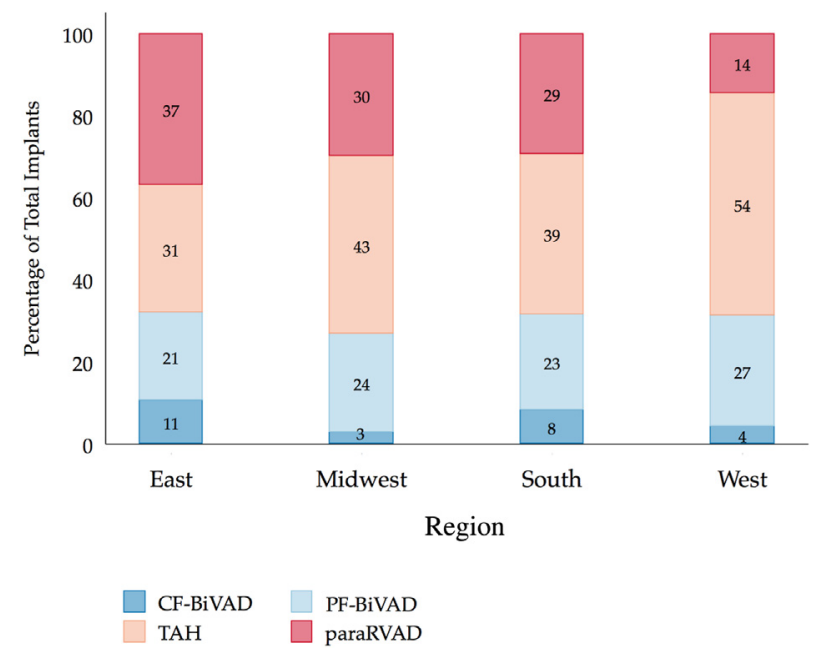

FIGURE 2. BiVAD preference, based on geographic region. East $=$ regions 1,2 , and 9; Midwest $=$ regions 7,8 , and 10; South $=$ regions 3,4 , and 11 ; and West $=$ regions 5 and 6 . Values within bars are $\mathrm{n}$ within region and device categories, Biventricular assist device; $C F-B i V A D$, continuous-flow BiVAD; TAH, total artificial heart; $P F-B i V A D$, pulsatile-flow biventricular assist device; paraRVAD, paracorporeal right ventricular assist device. similarly demonstrated nonischemic etiology as a significant predictor of post-LVAD RV failure. Such failure may be secondary to the global myocardial involvement observed in nonischemic cardiomyopathy, rather than the more-regional involvement observed in ischemic disease. In the latter, right coronary artery patency and resultant RV perfusion might be intact, leading to relatively preserved RV size and function. ${ }^{4,14}$

Patients requiring biventricular support were younger, and had a lower incidence of tobacco use and diabetes;

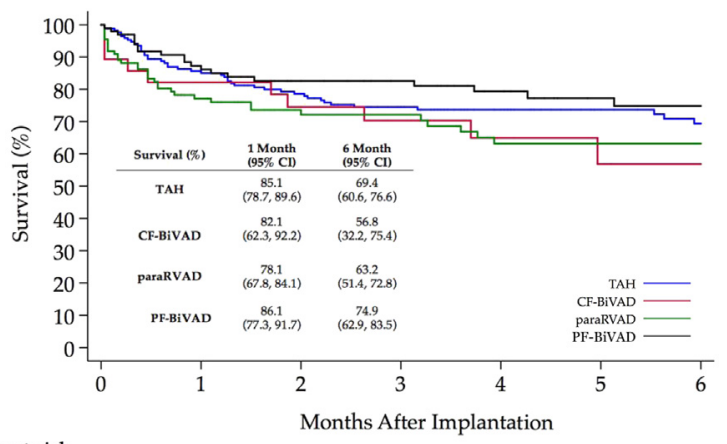

Number at risk

\begin{tabular}{|c|c|c|c|c|c|c|}
\hline ТАH 17 & 137 & 118 & 95 & 74 & 56 & 46 \\
\hline CF-BiVAD 28 & 23 & 19 & 16 & 10 & 7 & 6 \\
\hline paraRVAD 11 & 70 & 50 & 44 & 34 & 28 & 25 \\
\hline PF-BiVAD 98 & 76 & 62 & 54 & 43 & 32 & 26 \\
\hline
\end{tabular}

FIGURE 3. Postimplantation survival on BiVAD, based on device type. $C I$, Confidence interval; $T A H$, total artificial heart; $B i V A D$, biventricular assist device; $C F-B i V A D$, continuous-flow BiVAD; paraRVAD, paracorporeal right ventricular assist device; $P F-B i V A D$, pulsatile-flow biventricular assist device. 
TABLE 3. Independent predictors of mortality on biventricular assist device support

\begin{tabular}{|c|c|c|c|c|}
\hline \multirow[b]{2}{*}{ Variable } & \multicolumn{2}{|c|}{ Univariable analysis } & \multicolumn{2}{|c|}{ Multivariable analysis } \\
\hline & HR $(95 \%$ CI $)$ & $P$ value & OR $(95 \%$ CI $)$ & $P$ value \\
\hline Support Type & & 183 & - & \\
\hline CF-BiVAD & $1.40(0.71,2.79)$ & .329 & & \\
\hline paraRVAD & $1.37(0.87,2.14)$ & .173 & & \\
\hline PF-BiVAD & $0.79(0.46,1.33)$ & .368 & & \\
\hline Age & $1.17(0.803-1.71)$ & .41 & - & \\
\hline Male Gender & $1.00(0.65-1.54)$ & .999 & - & \\
\hline BSA & $1.47(1.1 .01-2.15)$ & .044 & $2.12(1.4,3.92)$ & $.017 *$ \\
\hline Ischemic Etiology & $1.2(0.81-1.79)$ & .368 & - & \\
\hline Race & & .720 & - & \\
\hline Black & $1.17(0.75-1.83)$ & & 一 & \\
\hline Other & $0.908(0.47-1.76)$ & & - & \\
\hline Diabetes & $1.42(0.95-2.13)$ & .091 & $1.33(0.89,2.01)$ & .166 \\
\hline Blood Type O & $1.07(0.735-1.56)$ & .719 & - & \\
\hline History of Smoking & $1.03(0.69-1.51)$ & .895 & - & \\
\hline Region & & .338 & - & \\
\hline West & $0.68(0.41-1.12)$ & & - & \\
\hline Midwest & $0.62(0.34-1.14)$ & & - & \\
\hline South & $0.68(0.41-1.12)$ & & - & \\
\hline & $0.977(0.841-1.135)$ & .762 & - & \\
\hline
\end{tabular}

East $=$ regions 1, 2, and 9; Midwest $=$ regions 7, 8, and 10; South $=$ regions 3, 4, and 11 ; and West $=$ regions 5 and 6 . Only variables at the $P<.10$ level in univariable analyses were included in the multivariable analysis. Reference category is TAH for Support Type is TAH, White for Race and East for Regions. HR, Hazard ratio; $C I$, confidence interval; $O R$, odds ratio; $B S A$, body surface area. $* P<.05$.

however, these findings could additionally be related to a higher incidence of the nonischemic etiology observed in this cohort. In addition, we found that overall cardiac index was lower in patients requiring biventricular support, which may point to a more severe cardiomyopathy in these individuals, because 2 ventricles in series are failing, compared with a single ventricular failure. Fitzpatrick and colleagues ${ }^{7}$ have additionally suggested low cardiac index as an independent predictor of post-LVAD RV failure.

Finally, in our study, end-organ function, including higher bilirubin and lower albumin levels, was noted in

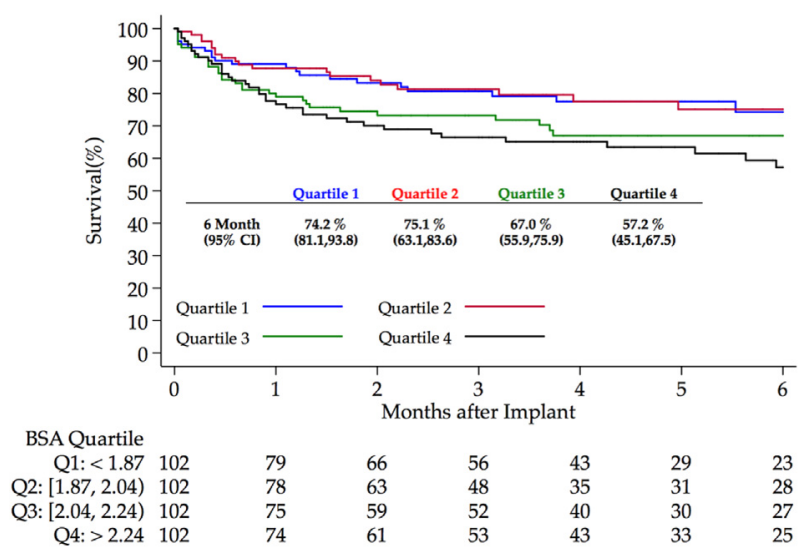

FIGURE 4. Postimplantation survival on BiVAD, based on BSA quartile. $C I$, Confidence interval; $B S A$, body surface area. patients requiring biventricular assistance or replacement. This finding is not unexpected, because hepatic congestion is commonly observed in patients who have RV failure. The Michigan RV failure score, as well as other prediction models, have incorporated liver function tests including aspartate aminotransferase and bilirubin into their risk modeling. ${ }^{6,15}$ Postimplantation survival of patients requiring biventricular support was significantly worse than that for patients requiring CF-LVAD alone, in our analysis of the United Network for Organ Sharing dataset, which is consistent with the recent report of the Interagency Registry for Mechanically Assisted Circulatory Support ${ }^{14}$ demonstrating a $56 \%$ survival rate at 6 months for BiVAD patients, compared with $86 \%$ in LVAD patients.

A comparison of the common configurations utilized for biventricular support as a bridge-to-transplantation showed significant differences in BSA, ischemic etiology, race, and geographic region among BiVAD groups. The lowest levels of BSA were noted in the PF-BiVAD group, which is not unexpected, ${ }^{12}$ because this pump is extracorporeal, and is designed to fit in patients who have BSA as low as $0.73 \mathrm{~m}^{2}$. The paracorporeal-RVAD and PF-BiVAD groups had more patients who had ischemic etiology, compared with patients who had TAH and CF-BiVAD. One potential explanation for this finding could be a higher incidence of reoperation and resultant adhesions in the ischemic cohort, which may favor use of an paracorporeal-RVAD for its ease of implantation surgically.

Significant regional differences were found in utilization of BiVAD options. Choice of device configuration did not differ based on waitlist times, suggesting that regional differences were likely secondary to center experience or preference rather than to logistics related to transplantation waitlist times. Although we found an association of device preference with race, this relationship could be related to differences in race of the populations within each geographic region. In parallel with the increasing incidence of CF-LVAD implantation, we noted an increase in use of BiVADS, although overall use of the PF-BiVAD configuration has been declining.

Another finding of this study was an association of body size and mortality with BiVAD support. A possible explanation for this finding is that patients with a large body size require higher cardiac output, and under demanding situations, such as sepsis and vasoplegia, which are not uncommon in these patient populations. Therefore, flow provided by the BiVADS simply may not be enough to meet the physiologic need in these circumstances.

Patients with large body sizes (BSA quartile 4) had higher mortality on PF-BiVAD support, ${ }^{16}$ which provides up to $7.0 \mathrm{~L} /$ minute maximum blood flow; TAH provides up to $9.5 \mathrm{~L} /$ minute. On the other hand, extracorporeal configurations including PF-BiVAD and paracorporealRVAD may be more favorable in patients who have small 
body sizes, owing to the technical ease of implantation. A smaller version of TAH, currently under clinical investigation, ${ }^{17}$ has been developed to facilitate placement of this device in patients who have a BSA $<1.7 \mathrm{~m}^{2}$.

Taken together, our findings suggest that body size should be taken into account in selection of an appropriate BiVAD configuration. The presence of specific clinical scenarios may additionally favor selection of 1configuration rather than another. For example, the presence of severe infiltrative cardiomyopathy, with small ventricular cavity size, postinfarction ventricular septal defect, or complex congenital heart conditions, may preclude use of CFBiVAD, paracorporeal-RVAD, or PF-BiVAD configurations. On the contrary, TAH may not be an appropriate choice in young nonischemic patients who have the potential likelihood of myocardial recovery and subsequent device explantation. ${ }^{18}$ Therefore, the clinical context always should be incorporated into decisions in selecting the appropriate BiVAD for each patient.

Retrospective analysis of a large, institutional clinical data registry carries known, inherent limitations. Important data that are relevant to right-heart physiology, including central venous pressure and echocardiographic measures (RV size, function, tricuspid annular plane systolic excursion, strain), were not available in the United Network for Organ Sharing dataset, nor were device-related complications, which are an important outcome measure. Although we found no differences in postimplantation or in posttransplantation survival among various device configurations, our study may not have had sufficient power to detect such differences, given the limited sample size in each device group.

In summary, our findings demonstrate comparable survival on device support and transplantation outcomes in patients undergoing various BiVAD configurations. Center preference seems to be more important for utilization of a specific configuration, compared with regional differences in waitlist times. Body size is an important determinant of cardiac output requirements and should be taken into account for device selection. Given the poor outcomes of patients who require biventricular support, ongoing research and technologic advancements, with improved device design, are needed to achieve superior outcomes in this population.

\section{Conflict of Interest Statement}

Y.N. received consulting fees from Thoratec Corporation (Pleasanton, Calif). All other authors have nothing to disclose with regard to commercial support.

This study was supported by Lisa and Mark Schwartz and the Program to Reverse Heart Failure at New York-Columbia Presbyterian Hospital/Columbia University.

\section{References}

1. Miller LW, Pagani FD, Russell SD, John R, Boyle AJ, Aaronson KD, et al: HeartMate II Clinical Investigators. Use of a continuous-flow device in patients awaiting heart transplantation. New Engl J Med. 2007;357:885-96.

2. Slaughter MS, Rogers JG, Milano CA, Russell SD, Conte JV, Feldman D, et al; HeartMate II Investigators. Advanced heart failure treated with continuous-flow left ventricular assist device. New Engl J Med. 2009;361:2241-51.

3. Kirklin JK, Naftel DC, Pagani FD, Kormos RL, Stevenson LW, Blume ED, et al. Sixth INTERMACS annual report: a 10,000-patient database. J Heart Lung Transplant. 2014;33:555-64.

4. Ochiai Y, McCarthy PM, Smedira NG, Banbury MK, Navia JL, Feng J, et al. Predictors of severe right ventricular failure after implantable left ventricular assist device insertion: analysis of 245 patients. Circulation. 2002;106(12 Suppl 1):I198-202.

5. Dang NC, Topkara VK, Mercando M, Kay J, Kruger KH, Aboodi MS, et al. Right heart failure after left ventricular assist device implantation in patients with chronic congestive heart failure. J Heart Lung Transplant. 2006;25:1-6.

6. Matthews JC, Koelling TM, Pagani FD, Aaronson KD. The right ventricular failure risk score: a pre-operative tool for assessing the risk of right ventricular failure in left ventricular assist device candidates. J Am Coll Cardiol. 2008;51: 2163-72.

7. Fitzpatrick JR III, Frederick JR, Hiesinger W, Hsu VM, McCormick RC, Kozin ED, et al. Early planned institution of biventricular mechanical circulatory support results in improved outcomes compared with delayed conversion of a left ventricular assist device to a biventricular assist device. J Thorac Cardiovasc Surg. 2009;137:971-7.

8. Kormos RL, Teuteberg JJ, Pagani FD, Russell SD, John R, Miller LW, et al; HeartMate II Clinical Investigators. Right ventricular failure in patients with the HeartMate II continuous-flow left ventricular assist device: incidence, risk factors, and effect on outcomes. J Thorac Cardiovasc Surg. 2010;139: 1316-24.

9. Copeland JG, Smith RG, Arabia FA, Nolan PE, Sethi GK, Tsau PH, et al; CardioWest Total Artificial Heart Investigators. Cardiac replacement with a total artificial heart as a bridge to transplantation. New Engl J Med. 2004; 351:859-67.

10. Loforte A, Montalto A, Lilla Della Monica P, Musumeci F. Simultaneous temporary CentriMag right ventricular assist device placement in HeartMate II left ventricular assist system recipients at high risk of right ventricular failure. Interact Cardiovasc Thorac Surg. 2010;10:847-50.

11. Krabatsch T, Potapov E, Stepanenko A, Schweiger M, Kukucka M, Huebler M et al. Biventricular circulatory support with two miniaturized implantable assist devices. Circulation. 2011;124(11 Suppl):S179-86.

12. Tsukui H, Teuteberg JJ, Murali S, McNamara DM, Buchanan JR, Winowich S, et al. Biventricular assist device utilization for patients with morbid congestive heart failure: a justifiable strategy. Circulation. 2005;112(9 Suppl):I65-72.

13. Schulze PC, Kitada S, Clerkin K, Jin Z, Mancini DM. Regional differences in recipient waitlist time and pre- and post-transplant mortality after the 2006 United Network for Organ Sharing policy changes in the donor heart allocation algorithm. JACC Heart Fail. 2014;2:166-77.

14. Cleveland JC Jr, Naftel DC, Reece TB, Murray M, Antaki J, Pagani FD, et al Survival after biventricular assist device implantation: an analysis of the Interagency Registry for Mechanically Assisted Circulatory Support database. J Heart Lung Transplant. 2011;30:862-9.

15. Kavarana MN, Pessin-Minsley MS, Urtecho J, Catanese KA, Flannery M, $\mathrm{Oz} \mathrm{MC}$, et al. Right ventricular dysfunction and organ failure in left ventricular assist device recipients: a continuing problem. Ann Thorac Surg. 2002;73: 745-50.

16. Gemmato CJ, Forrester MD, Myers TJ, Frazier OH, Cooley DA. Thirty-five years of mechanical circulatory support at the Texas Heart Institute: an updated overview. Tex Heart Inst J. 2005;32:168-77.

17. Spiliopoulos S, Dimitriou AM, Guersoy D, Koerfer R, Tenderich G. Expanding applicability of total artificial heart therapy: the 50-cc SynCardia Total Artificial Heart. Ann Thorac Surg. 2015;100:e55-7.

18. Boehmer JP, Starling RC, Cooper LT, Torre-Amione G, Wittstein I, Dec GW, et al; IMAC Investigators. Left ventricular assist device support and myocardial recovery in recent onset cardiomyopathy. J Card Fail. 2012;18:755-61.

Key Words: ventricular assist device, right ventricular failure, biventricular support 


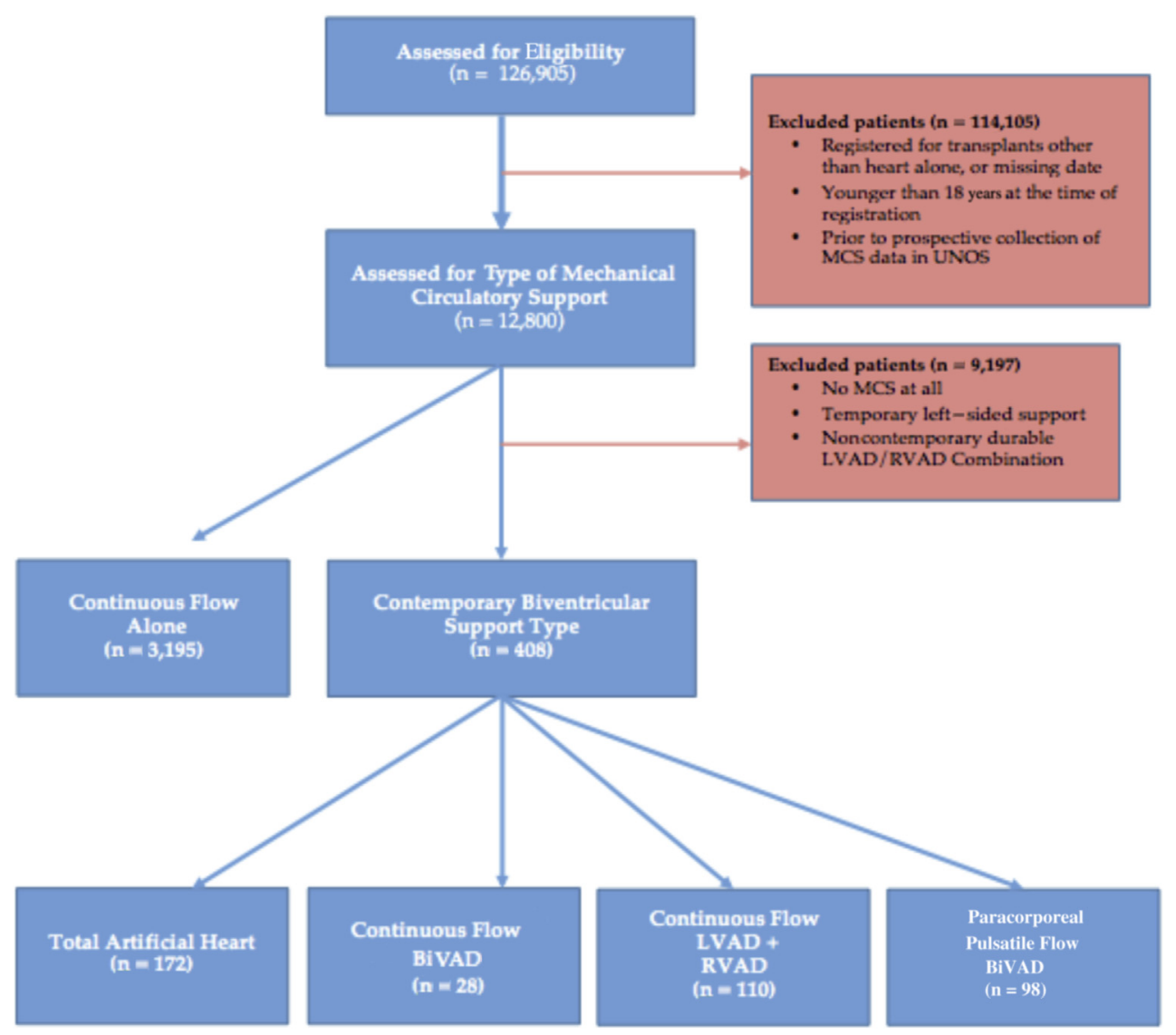

FIGURE E1. Identification of the analysis cohort from the UNOS database. MCS, Mechanical circulatory support; UNOS, United Network for Organ Sharing; $L V A D$, left ventricular assist device; RVAD, right ventricular assist device; BiVAD, biventricular assist device.
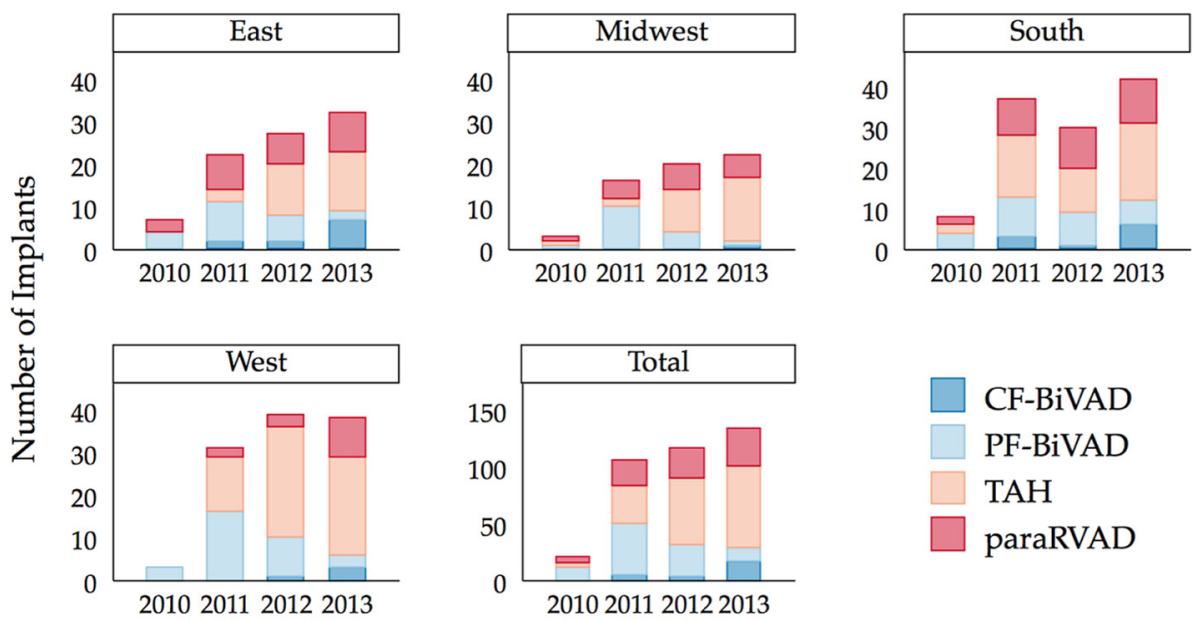

CF-BiVAD

PF-BiVAD

TAH

paraRVAD

FIGURE E2. Changing trends in use of BiVAD types. $C F$-BiVAD, Continuous-flow biventricular assist device; $P F-B i V A D$, pulsatile-flow biventricular assist device; $T A H$, total artificial heart; paraRVAD, paracorporeal right ventricular assist device. 


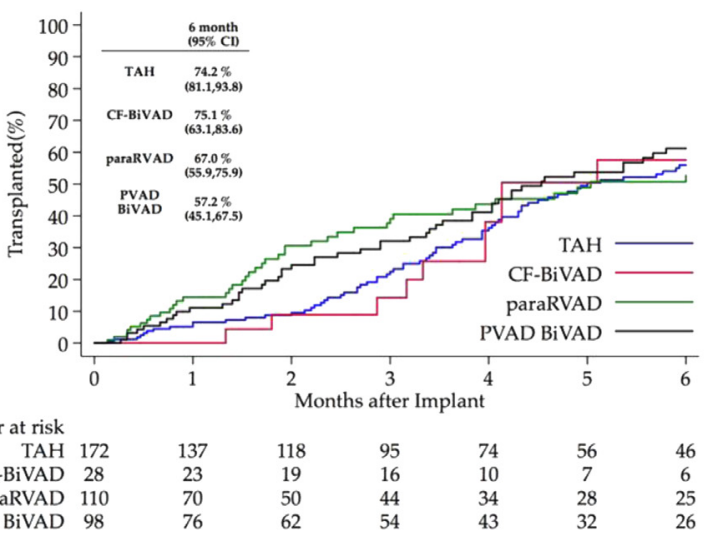

TABLE E1. Utilization of biventricular support devices, by UNOS region and average wait time for status $1 \mathrm{~A} / 1 \mathrm{~B}$

\begin{tabular}{|c|c|c|c|c|c|}
\hline $\begin{array}{l}\text { UNOS } \\
\text { region }\end{array}$ & TAH & CF-BiVAD & paraRVAD & PF-BiVAD & $\begin{array}{c}\text { Status } \\
\text { 1A/1B wait } \\
\text { time (d)* }\end{array}$ \\
\hline 1 (East) & $5(25.0)$ & $4(20.0)$ & $4(20.0)$ & $7(35.0)$ & 113 \\
\hline 2 (East) & $12(26.1)$ & $6(13.0)$ & $13(28.3)$ & $15(32.6)$ & 82 \\
\hline 3 (South) & $2(12.5)$ & $2(12.5)$ & $6(37.5)$ & $6(37.5)$ & 77 \\
\hline 4 (South) & $10(38.5)$ & $6(23.1)$ & $4(15.4)$ & $6(23.1)$ & 100 \\
\hline 5 (West) & $50(50.5)$ & $3(3.0)$ & $16(16.2)$ & $30(30.3)$ & 34 \\
\hline 6 (West) & $14(73.7)$ & $2(10.5)$ & $1(5.3)$ & $2(10.5)$ & 86 \\
\hline 7 (Midwest) & $11(44.0)$ & $1(4.0)$ & $3(12.0)$ & $10(40.0)$ & 95 \\
\hline 8 (Midwest) & $11(64.7)$ & $0(0.0)$ & $5(29.4)$ & $1(5.9)$ & 59 \\
\hline 9 (East) & $15(40.5)$ & $1(2.7)$ & $21(56.8)$ & $0(0.0)$ & 144 \\
\hline 10 (Midwest) & $7(28.0)$ & $1(4.0)$ & $12(48.0)$ & $5(20.0)$ & 70 \\
\hline 11 (South) & 35 (44.9) & $2(2.6)$ & $25(32.1)$ & $16(20.5)$ & 79 \\
\hline
\end{tabular}

TABLE E2. Interaction analysis between BiVAD type and BSA

FIGURE E3. A, Bridge-to-transplantation rate; (B) Posttransplantation survival of patients with various BiVAD types. TAH, Total artificial heart; $C F-B i V A D$, continuous-flow biventricular assist device; paraRVAD, paracorporeal right ventricular assist device; $P F-B i V A D$, pulsatile-flow biventricular assist device.

\begin{tabular}{lll}
\hline \multicolumn{1}{c}{ Variable } & HR $(\mathbf{9 5} \% \mathbf{C I})$ & $\boldsymbol{P}$ value \\
\hline Support type & & \\
CF-BiVAD & $1.68(0.36,7.93)$ & .510 \\
paraRVAD & $1.53(0.57,4.08)$ & .394 \\
PF-BiVAD & $0.41(0.11,1.56)$ & .193 \\
BSA quartile (range) & & \\
$2(1.87,2.04)$ & $1.12(0.45,2.78)$ & .811 \\
$3(2.04,2.24)$ & $1.64(0.75,1.83)$ & .261 \\
$4(\geq 2.24)$ & $1.03(0.41,2.55)$ & .957 \\
Support type, by BSA quartile & & \\
CF-BiVAD & & \\
2 & $1.06(0.14,7.89)$ & .955 \\
3 & $1.03(0.02,2.94)$ & .258 \\
4 & $1.37(0.20,9.44)$ & .748 \\
paraRVAD & & \\
2 & $0.53(0.12,2.22)$ & .382 \\
3 & $0.76(0.21,2.74)$ & .673 \\
4 & $1.50(0.41,5.43)$ & .539 \\
PF-BiVAD & & \\
2 & $0.45(0.04,5.20)$ & .525 \\
3 & $1.36(0.27,7.24)$ & .716 \\
4 & $6.56(1.37,31.47)$ & $.019 *$ \\
\hline
\end{tabular}

Reference for support type is total artificial heart. Reference for BSA is the first quartile. $H R$, Hazard ratio; $C I$, confidence interval; $C F-B i V A D$, continuous-flow biventricular assist device; paraRVAD, paracorporeal right ventricular assist device; $P F$ $B i V A D$, pulsatile-flow biventricular assist device; $B S A$, body surface area. $* P<.05$. 